\title{
Reactions with Aminobenzoic Acids via Diazonium Salts Open New Routes to Bio-Derived Aromatics
}

\author{
Anthony Farlow ${ }^{1,2}$, Jens Olaf Krömer ${ }^{3,4^{*}}$ \\ ${ }^{1}$ School of Chemical and Molecular Biosciences, The University of Queensland, Brisbane, Australia \\ ${ }^{2}$ Instituto de Biociências, Universidade Estadual Paulista “Júlio de Mesquita Filho" (UNESP), Botucatu, Brazil \\ ${ }^{3}$ Centre for Microbial Electrochemical Systems, The University of Queensland, Brisbane, Australia \\ ${ }^{4}$ Advanced Water Management Centre, The University of Queensland, Brisbane, Australia \\ Email: ${ }^{\text {jj.kromer@uq.edu.au }}$
}

Received 24 March 2016; accepted 23 May 2016; published 27 May 2016

Copyright (C) 2016 by authors and Scientific Research Publishing Inc.

This work is licensed under the Creative Commons Attribution International License (CC BY).

http://creativecommons.org/licenses/by/4.0/

(c) (i) Open Access

\section{Abstract}

Aromatics have a broad application in our everyday life ranging from plastics, coatings and fibres, to food and pharmaceuticals. To date the bulk of these aromatics is derived from naphtha-based petrochemistry. However, recent progress in the fermentative production of metabolites using renewable resources and engineered microbes has enabled the production of bio-precursors, such as 4-amino benzoic acid (pABA) and 2-amino benzoic acid (oABA). In this work we explored the feasibility of Sandmeyer reactions for the conversion of pABA to terephthalic and oABA salicylic acid, providing two very important platform chemicals for the chemical and pharmaceutical industries. We could demonstrate that both acids can be obtained from the amino benzoic acids derived from the shikimate pathway in microbes and plants. Good conversions could be achieved using Sandmeyer reactions at mild conditions with biodegradable reagents and without organic solvents.

\section{Keywords}

Aminobenzoic Acid, Terephthalic Acid, Salycilic Acid, Sandmeyer Cyanations

\section{Introduction}

In nature, 4-aminobenzoic acid (pABA) and anthranilic acid (2-aminobenzoic acid, oABA) are aromatic inter-

\footnotetext{
*Corresponding author.
}

How to cite this paper: Farlow, A. and Krömer, J.O. (2016) Reactions with Aminobenzoic Acids via Diazonium Salts Open New Routes to Bio-Derived Aromatics. International Journal of Organic Chemistry, 6, 95-99. 
mediates that are derived from chorismic acid, an intermediate of the aromatic amino acid biosynthesis. pABA is a precursor in folate synthesis in bacteria, yeast and some plants and a precursor of Coenzyme Q [1] [2], while its isomer oABA is a precursor of the aromatic amino acid tryptophan. Chemically synthesized pABA currently finds application as a sun-blocker, functional food, in diagnostic tests [3] [4], dyes, drug design, and as crosslinking agent for polyurethane resins [5].

In recent years, the biotechnological production of pABA and oABA from sugar using bacteria or yeasts [5]-[7] has become a focal point in biotechnology and current yields are moving beyond proof-of-principle stages, opening the possibility of future applications, such as the use of the metabolites as a precursor for synthesis of more commonly used bulk compounds.

Two petrochemicals that stand out because of structural similarity to the bio-molecules pABA and oABA are terephthalic (TA) and salicylic acid (SA), respectively. Purified TA is one of the most important aromatic feedstocks in the chemical industry with an annual global market of over 50 Mio tonnes. TA is mainly synthesized through oxidation of p-xylene (Amoco process). Although SA was first identified in willow bark [8], most salicylic acid is now synthesized from phenol (generally obtained from petrochemicals) via the Kolbe-Schmitt reaction [9] [10] (Figure 1).

We hypothesized that by performing Sandmeyer cyanations on pABA and oABA and hydrolysing the resulting cyanobenzoic acids, it would be possible to synthesise the corresponding phthalic acids without the use of organic solvents and with easily degradable reagents. To further study this chemistry and the employment of the metabolites as chemical precursors, we carried out Sandmeyer cyanations and chlorinations on pABA and oABA, thus testing the utility of this process to synthesize phthalic acids and chlorobenzoic acids from biological precursors and avoiding the use of petrochemicals. Although straightforward, these processes have not been reported to date, nor has their utility for the industrial preparation of TA and SA been explored because they have not been economical to date compared to established processes using petrochemical feedstocks. However, there is now a growing awareness in the need to develop processes for the synthesis of sustainable feedstocks derived from renewable resources, and aminobenzoic acids from the shikimate pathway which satisfies that prerequisite.

\section{Experimental Section}

\subsection{Reagents and Analysis}

Analytical grade (A.R.) anthranilic acid and 4-aminobenzoic acid from Sigma-Aldrich were employed in this synthesis. Inorganic reagents (A.R. grade) were purchased from Univar. NMR were carried out in DMSO-D6 and $\mathrm{CDCl} 3$ using a $400 \mathrm{MHz}$ Oxford Cryogenics systems apparatus, and were calibrated to the respective solvent peaks [11]. Melting points are corrected to a commercial sample of salicylic acid.

\subsection{General Procedure for Synthesis of TA}

4-Aminobenzoic acid (5.00 g, $36.5 \mathrm{mmol})$ was suspended in sulfuric acid ( $0.50 \mathrm{M}, 72 \mathrm{ml})$ and allowed to sit for $18 \mathrm{~h}$. The suspension was cooled on ice. Cold sulfuric acid $(1.0 \mathrm{M}, 40 \mathrm{ml})$ was added to sodium nitrite (2.62 g, 37.9 mmol, 1.04 eq.) in cold water ( $40 \mathrm{ml}$ ) (CAUTION-some HNO2 evolution occurs). The resulting nitrous acid solution was added to the suspension of 4-aminobenzoic acid and the mixture stirred on ice until the solid had completely dissolved. Meanwhile, copper(II) sulfate pentahydrate (288 mg, $1.15 \mathrm{mmol}$ : 3\%) in water (5.0 $\mathrm{ml}$ ) was reduced to copper(I) sulfate using sodium bisulfite $(60 \mathrm{mg}, 0.58 \mathrm{mmol})$. The resulting copper(I) salt was added to potassium cyanide ( $4.10 \mathrm{~g}$, $87 \%$ pure by the Liebig test, $54.8 \mathrm{mmol}$ : 1.5 eq.) in cold water $(50 \mathrm{ml})$. The diazonium salt solution was neutralised with sodium bicarbonate $(9.70 \mathrm{~g})$ and then added to the copper(I) cyanide complex (CAUTION: excess acid may result in HCN formation), whereupon a gas was evolved slowly and

A<smiles>Cc1ccc(C)cc1</smiles>

$\mathrm{O}_{2}$, cat. $\mathrm{Co}^{2+}, \mathrm{Mn}^{2+}, \mathrm{Br}^{-}$in $\mathrm{CH}_{3} \mathrm{COOH}$, heat
B<smiles>O=C(O)c1cccc([IH]c2ccccc2)c1O</smiles>

1. $\mathrm{NaOH} / \mathrm{O}_{2} ; 2 . \mathrm{H}^{+}$

Figure 1. Current processes for the synthesis of TA (Scheme A) and SA (Scheme B). 
a dark precipitate formed. The reaction mixture was maintained at $0^{\circ} \mathrm{C}-5^{\circ} \mathrm{C}$ for a further $20 \mathrm{~h}$, after which the mixture was allowed to warm to room temperature. Hydrogen peroxide $(30 \% \mathrm{w} / \mathrm{v}, 10 \mathrm{ml})$ and sodium hydroxide (5.0 g) were added, dissolving the precipitate. The solution was filtered through a Whatman 541 paper the mixture was heated under reflux for $16 \mathrm{~h}$. Terephthalic acid was precipitated using $1 \mathrm{M}$ sulfuric acid (200 ml). The precipitate was collected by gravity filtration, washed with de-ionized water and allowed to dry. Yield = $5.56 \mathrm{~g}$ (>90\% pure by NMR, $30.1 \mathrm{mmol}$ : 82\%). 1H and 13C NMR were consistent with the literature [12].

Short-path vacuum sublimation $\left(250^{\circ} \mathrm{C}, 0.1 \mathrm{mbar}\right.$; lit. [13] sublimes at $407^{\circ} \mathrm{C}$ at $760 \mathrm{~mm} \mathrm{Hg}$ ) slowly afforded an off-white solid of $>95 \%$ purity by NMR.

\subsection{General Procedure for Synthesis of SA}

Sodium nitrite ( $2.64 \mathrm{~g}, 38.3 \mathrm{mmol}$ ) was added to a stirred suspension of 4-aminobenzoic acid (5.00 g, 36.5 mmol) in sulfuric acid $(1.0 \mathrm{M}, 55 \mathrm{ml})$ at $0^{\circ} \mathrm{C}$. The ice bath was removed and mixture was heated under reflux for $5 \mathrm{~h}$. A solid was obtained upon cooling, which was recrystallized from hot water to afford salicylic acid ( $3.05 \mathrm{~g}$, $61 \%$ ), $\mathrm{mp} 156.5^{\circ} \mathrm{C}$ (lit. [14] $159^{\circ} \mathrm{C}$ for SA). $1 \mathrm{H}$ and $13 \mathrm{C}$ NMR spectra were identical to a commercial sample.

\section{Results and Discussion}

\subsection{Conversion of pABA to TA}

The corresponding diazonium salts formed by the reaction of acid pABA with sodium nitrite was uncharacteristically sensitive to nucleophilic attack by water and, under alkaline conditions, excess nitrite. Consequently, hydroxylation nitration was competing processes in these Sandmeyer reactions. 4-Hydroxybenzoic acid was a significant by-product of the chlorination of pABA, even when a ten-fold excess of $\mathrm{HCl}$ was used, making the synthesis of 4-chlorobenzoic acid from pABA unattractive. Fortunately, 4-cyanobenzoic acid (and correspondingly, terephthalic acid) with low levels of impurities could be obtained when cyanation was carried out with careful control of temperature and $\mathrm{pH}$ in the presence of catalytic copper(I) and an excess of potassium cyanide. In order to limit nitration, we found that the best results were attained when nitrous acid was generated in situ from sulfuric acid and sodium nitrite prior to addition to pABA in cold dilute sulfuric acid. Neutralization of the corresponding diazonium salt with sodium bicarbonate and transfer of the diazonium salt to sodium cyanide in the presence of copper(I) sulfate, and heating under reflux with sodium hydroxide, led to the formation of sodium terephthalate (Figure 2).

Good yields (approximately 80\%) of crude TA could then be precipitated with $1 \mathrm{M}$ sulfuric acid, resulting in a one-pot aqueous synthesis of terephthalic acid from solution with inexpensive and environmentally benign reagents. Both the synthesis and the hydrolysis of 4-cyanobenzoic acid have been infrequently reported [15]-[17], but this is the first reported example of the synthesis of terephthalic acid from pABA as continuous process.

The precipitate generated by this procedure was more than $90 \%$ pure by NMR, with trace quantities of several para-substituted aromatics also present. Several processes have previously been reported for the purification of terephthalic acid generated from the oxidation of p-xylene [18]. However, commercial processes for the purification of TPA to the highly pure material necessary for polymerization (impurities at concentrations of less than $25 \mathrm{ppm}$ ) involves several steps that require high-pressure reactors (for example, hydrogenation in water at $250^{\circ} \mathrm{C}$ ), and are anyhow optimized for side products formed during the AMOCO process such as 4-carboxybenzoic acid [18]. As such, purification processes required for polymer-grade TPA will need to be re-assessed on an industrial scale were the synthesis of TPA from pABA to be commercialized. However, the authors did

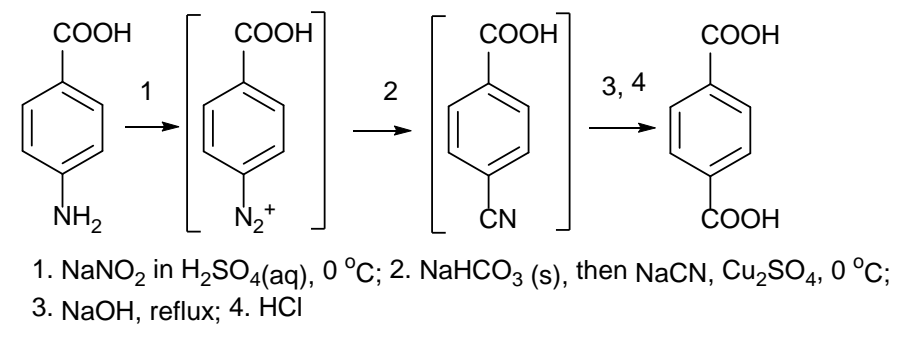

Figure 2. Conversion of pABA to TA. 


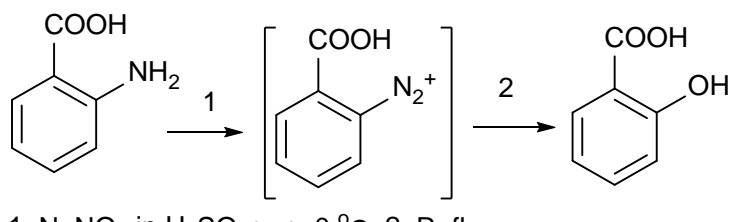

1. $\mathrm{NaNO}_{2}$ in $\mathrm{H}_{2} \mathrm{SO}_{4}(\mathrm{aq}), 0^{\circ} \mathrm{C} ; 2$. Reflux

Figure 3. Conversion of oABA to SA.

observe that the purity of TPA generated by this process could be improved significantly by sublimation under vacuum and we suggest that this may prove to be a useful purification step.

\subsection{Conversion of oABA to SA}

The diazonium salts of pABA were less susceptible to nucleophilic attack by the chloride ion, and we could not prevent significant levels of hydroxylation when attempting to synthesise 4-chlorobenzoic acid. The diazonium salt of oABA was even more susceptible, and we could not produce useful amounts of phthalic acid using the same methodology as reported above. However, although the diazonium salt of oABA is too susceptible to hydroxylation for the Sandmeyer reaction to be useful for the production of phthalic acid or more diverse products, this susceptibility does provide a particularly facile route to 2-hydroxybenzoic acid (salicylic acid). Catalytic cuprous salts were not required for this hydroxylation. oABA could be converted into SA simply by the addition of sodium nitrite to oABA in aqueous acid and heating the mixture under reflux (Figure 3). Highly pure SA could be recovered in approximately $60 \%$ yield by recrystallization from water. Unlike the above mentioned TA, SA can also be directly produced in fermentation [19], but the presented method provides an option to develop bio-based oABA into a platform chemical than can then be used directly or converted to different products.

\section{Conclusion}

The shikimate pathway derived aminobenzoic acids pABA and oABA have become interesting target compounds for biotechnology. We show here that they are suitable precursors for synthesis of terephthalic and salicylic acids, respectively. The reported Sandmeyer reactions are free of organic solvents and low excesses of inexpensive reagents which, although toxic, can be degraded into harmless products. This work lays the basis for industrial chemists to develop a scalable process for the synthesis of terephthalic acid and salicylic acid from renewable resources.

\section{Acknowledgements}

The authors want to acknowledge Prof. Paul Bernhardt (The University of Queensland) and Prof. Margarida Saeki (UNESP) for supporting this work with access to infrastructure, and Miss Jessica Bilyj (The University of Queensland) for NMR analysis. The authors also acknowledge early discussion about this work with Dr. Katharina Ladewig (University of Melbourne). This work was funded by the Australian Research Council (DE120101549).

\section{References}

[1] Hanson, A.D. and Gregory III., J.F. (2011) Folate Biosynthesis, Turnover, and Transport in Plants. Annual Review of Plant Biology, 62, 105-125. http://dx.doi.org/10.1146/annurev-arplant-042110-103819

[2] Marbois, B., Xie, L.X., Choi, S., Hirano, K., Hyman, K. and Clarke, C.F. (2010) Para-Aminobenzoic Acid Is a Precursor in Coenzyme Q6 Biosynthesis in Saccharomyces cerevisiae. The Journal of Biological Chemistry, 285, 2782727838. http://dx.doi.org/10.1074/jbc.M110.151894

[3] Hu, M.L., Chen, Y.K., Chen, L.C. and Sano, M. (1995) Para-Aminobenzoic Acid Scavenges Reactive Oxygen Species and Protects DNA against UV and Free Radical Damage. The Journal of Nutritional Biochemistry, 6, 504-508. http://dx.doi.org/10.1016/0955-2863(95)00082-B

[4] Mackie, B.S. and Mackie, L.E. (1999) The PABA Story. Australasian Journal of Dermatology, 40, 51-53. http://dx.doi.org/10.1046/j.1440-0960.1999.00319.x

[5] Koma, D., Yamanaka, H., Moriyoshi, K., Sakai, K., Masuda, T., Sato, Y., Toida, K. and Ohmoto, T. (2014) Production 
of p-Aminobenzoic Acid by Metabolically Engineered Escherichia coli. Bioscience, Biotechnology, and Biochemistry, 78, 350-357. http://dx.doi.org/10.1080/09168451.2014.878222

[6] Krömer, J.O., Nunez-Bernal, D., Averesch, N.J., Hampe, J., Varela, J. and Varela, C. (2013) Production of Aromatics in Saccharomyces cerevisiae-A Feasibility Study. Journal of Biotechnology, 163, 184-193. http://dx.doi.org/10.1016/j.jbiotec.2012.04.014

[7] Balderas-Hernandez, V.E., Sabido-Ramos, A., Silva, P., Cabrera-Valladares, N., Hernandez-Chavez, G., Baez-Viveros, J.L., Martinez, A., Bolivar, F. and Gosset, G. (2009) Metabolic Engineering for Improving Anthranilate Synthesis from Glucose in Escherichia coli. Microbial Cell Factories, 8, 19. http://dx.doi.org/10.1186/1475-2859-8-19

[8] Rishton, G.M. (2008) Natural Products as a Robust Source of New Drugs and Drug Leads: Past Successed and Present Day Issues. American Journal of Cardiology, 101, S43-S49. http://dx.doi.org/10.1016/j.amjcard.2008.02.007

[9] Weber, M., Weber, M. and Kleine-Boymann, M. (2004) Phenol. In: Ullmann's Encyclopedia of Industrial Chemistry, Wiley-VCH GmbH \& Co., Weinheim. http://dx.doi.org/10.1002/14356007.a19_299.pub2

[10] Boullard, O., Leblanc, H. and Besson, B. (2000) Salicylic Acid. In: Ullmann's Encyclopedia of Industrial Chemistry, Wiley-VCH GmbH \& Co., Weinheim. http://dx.doi.org/10.1002/14356007.a23_477

[11] Gottleib, H.E., Kotlyar, V. and Nudelman, A. (1997) NMR Chemical Shifts of Common Laboratory Solvents as Trace Impurities. The Journal of Organic Chemistry, 6, 7512-7515. http://dx.doi.org/10.1021/jo971176v

[12] Crisóstomo, C., Crestani, M.G. and García, J. (2007) The Catalytic Hydration of 1,2-, 1,3- and 1,4-Dicyanobenzenes Using NIckel(0) Catalysts. Journal of Molecular Catalysis A: Chemical, 266, 139-148. http://dx.doi.org/10.1016/j.molcata.2006.10.054

[13] Lucchesi, C.A. and Lewis, W.T. (1968) Latent Heat of Sublimation of Terephthalic Acid from Differential Thermal Analysis Data. Journal of Chemical \& Engineering Data, 13, 389-391. http://dx.doi.org/10.1021/je60038a026

[14] Hoye, J.A., Gupta, A. and Myrdal, P.B. (2008) Solubility of Solid Solutes in HFA-134a with a Correlation to PhysicoChemical Properties. Journal of Pharmaceutical Sciences, 97, 198-208. http://dx.doi.org/10.1002/jps.21080

[15] Miller, R.H. and Gisvold, O. (1953) An Improved Procedure for the Preparation of p-Cyanobenzoic Acids. Journal of the American Pharmaceutical Association (Scientific ed.), 42, 367-369. http://dx.doi.org/10.1002/jps.3030420616

[16] Wang, Q., Li, Y., Fang, F. and Shi, D. (1993) Synthesis of Ethyl 4-Cyanobenzoate. Chemical Reagents, 15, 256.

[17] Schou, S.C. (2009) Fast and Efficient Synthesis of 14 Clabelled Benzonitriles and Their Corresponding Acids. Journal of Labelled Compounds and Radiopharmaceuticals, 52, 173-176. http://dx.doi.org/10.1002/jlcr.1585

[18] Tomás, R.A.F., Bordado, J.C.M. and Gomes, J.F.P. (2013) p-Xylene Oxidation to Terephthalic Acid: A Literature Review Oriented toward Process Optimization and Development. Chemical Reviews, 113, 7421-7469. http://dx.doi.org/10.1021/cr300298j

[19] Lin, Y., Sun, X., Yuan, Q. and Yan, Y. (2014) Extending Shikimate Pathway for the Production of Muconic Acid and Its Precursor Salicylic Acid in Escherichia coli. Metabolic Engineering, 23, 62-69.

http://dx.doi.org/10.1016/j.ymben.2014.02.009 